\title{
Effect of Metformin and Clomiphene Citrate in Improving Fertility in Subfertile Women with Polycystic Ovary Syndrome: A Randomized Controlled Trial
}

\author{
HASINA BEGUM ${ }^{1}$, T.A. CHOWDHURY ${ }^{2}$, FERDOUSI BEGUM ${ }^{3}$, SHAMSUN NAHAR BEGUM ${ }^{4}$, \\ NAZNEEN KABIR ${ }^{5}$, MD. ABIDUL HAQUE ${ }^{6}$
}

\begin{abstract}
:
Objective: The main aim of this study was to compare the effect of metformin and clomiphene citrate on ovulation and conception rate in PCOS patients.

Methodology: This randomized controlled trial was undertaken in the infertility outpatient department in Institute of Child and Maternal Health (ICMH), Dhaka during the period from January 2012 to December 2012.

Total 71 PCOS women based on Rotterdam criteria were selected after randomization. They were divided into two groups - Group I $(n=35)$ received metformin $500 \mathrm{mg}$ per oral thrice daily and Group II $(n=36)$ received clomiphene citrate $100 \mathrm{mg}$ orally per day from $D_{2}$ for five days up-to six months.

Results: Baseline characteristics of both sample groups were almost similar. Ovulation was confirmed by measuring $D_{21}$ serum progesterone. Cumulative ovulation rate over six months period was not statistically different ( $57.14 \%$ and $61.11 \%) ;(P=0.115)$, and pregnancy rate was (34.28\% and 42.85\%); ( $P=0.521$ ) respectively.

Conclusion: Metformin has been found to be as effective as clomiphene citrate in terms of ovulation (57.14 \% and 61.11\%); and pregnancy rate (34.28\% and $42.85 \%$ ) respectively.
\end{abstract}

\section{Introduction:}

Polycystic ovary syndrome (PCOS) is one of the most common endocrinopathy ${ }^{1}$, affecting $5-10 \%$ of women of reproductive age $^{2}$. It is a common cause of anovulatory infertility ${ }^{3}$. The 2004 Rotterdam criteria for the diagnosis of PCOS required two of the following characteristics: Oligo and/or anovulation, hyperandrogenism (clinical or biochemical), polycystic ovaries with exclusion of other causes of androgen excess.

Insulin resistance with compensatory hyperinsulinemia and chronic anovulation are the pivotal features of
$\mathrm{PCOS}^{4}$. According to Polson Prevalence of PCOS is approximately $20-33 \%$ in general population ${ }^{5}$. Highest prevalence of PCOS has been found (52\%) among South Asian women ${ }^{6}$. Chowdhury and Nargis in their study (1998) at Bangladesh found $28.81 \%$ of infertile women diagnosed as cases of PCOS ${ }^{7}$.

Clomiphene citrate is the first agent used for ovulation induction in anovulatory PCOS women for many years ${ }^{8}$. More recently metformin, an oral biguanide used for type-II diabetes mellitus has been shown to assist ovulatory cycles in anovulatory $\mathrm{PCOS}^{9}$. It increases peripheral glucose uptake and utilization and thereby reduces insulin resistance.

1. Registrar, Gynae \& Obs, ICMH, Dhaka

2. Professor \& Head, Gynae \& Obs, BIRDEM

3. Ex-Professor, Gynae \& Obs, ICMH, Dhaka

4. Professor \& Head, Gynae \& Obs, SSMC, Dhaka

5. Professor \& Head, Gynae \& Obs, ICMH,Dhaka

6. Professor of Epidemiology, ICMH, Dhaka 
Reproductive endocrinologists are increasingly adopting metformin for the treatment of infertility in PCOS. Homburg presents a clear and cogent argument for the use of metformin in the treatment of $\mathrm{PCOS}^{10}$. As Homburg points out, individual studies have shown that metformin alone can restore regular menstrual cycles and reinstate ovulation in $25-95 \%$ cases $^{11}$. Recent evidence suggests that metformin is effective as first-line therapy for improving ovulation in PCOS women ${ }^{9,12}$, improves fertility ${ }^{13,14}$ and may even decrease the high rate of early pregnancy loss ${ }^{15,16}$ and incidence of gestational diabetes ${ }^{15,17,18}$.

So aim of this study was to evaluate and compare the effect of metformin with clomiphene citrate on ovulation and conception rate in $\mathrm{PCOS}$ patients.

\section{Materials and methods:}

This randomized controlled trial was undertaken in the infertility outpatient department in ICMH, Dhaka during the period from January 12 to December 12. Total 71 PCOS women based on Rotterdam criteria were selected after randomization. During study period out of total 817 subfertile women, 105 PCOS women were enrolled (12.85\%). Thirty four patients were excluded because they did not meet the inclusion criteria and refused to participate in the study. Inclusion criteria were subfertile women with PCOS between 20-35 yrs of ages and diagnosis of PCOS according to Rotterdam criteria. Exclusion criteria were: Age >35yrs; Hypo or hyperthyroidism, hyperprolactinaemia, diabetes mellitus and male factor infertility.

Randomization was done upon 71 participants by picking equal number of envelope labeled A, B assigned to metformin and clomiphene citrate. Finally 35 women in Group I (Metformin) and 36 women in Group II (Clomiphene citrate) were included for analysis.

Before entry into the study, height, weight, BMI and Waist-to-hip ratio (WHR) of all participants were measured. Serum FSH, LH level, thyroid function test and serum prolactin was performed at initial visit before commencement of study medications. Patients were instructed to take the study medications at least 6 months and follow their usual diet and physical activity.
Metformin given at a dose of 500mg thrice daily (Group I). The patients were instructed to take the tablets with their meals. Clomiphene citrate was given at a dose of 100mg daily for five days started from second day of menstruation following spontaneous or after progesterone withdrawal bleeding. Patients were asked to make a telephone call once they had a menstrual period. Patients were advised for intercourse during the fertile period. Ovulation was confirmed by measuring $D_{21}$ serum progesterone level. A value $5 \mathrm{ng} /$ $\mathrm{ml}$ was considered that ovulation took place. In both groups urine was tested for pregnancy 7 days after missed period. If pregnancy test was positive drug were discontinued. Otherwise treatment was continued as per previous schedule. In both regimen treatment was continued for 6 months. All other necessary information was noted in data collection sheet.

Prior to commencement of this study, the research protocol was approved by ethical clearance committee of ICMH. The procedure and benefits of this study was explained to the patients in easily understandable way by local language. Informed consent was taken from each patient. Confidentiality of data was strictly maintained.

The Statistical Package for Social Science (SPSS 20.0) was used for statistical analysis.Data was expressed as mean $\pm S D$ and statistical analysis for ovulation and pregnancy outcomes were performed by $\chi^{2}$ (chi square) test. Patient characteristics were analyzed with ' $t$ ' test. A P value of $<0.05$ was considered as significant.

\section{Results:}

Table-I shows baseline characteristics regarding age, BMI, waist-to-hip ratio, type of infertility and duration of infertility, which were similar in both groups. Baseline hormone like serum FSH, LH, prolactin, TSH and biochemical parameter like blood sugar within the study groups shown in Table-II. These were similar in both the groups. Table-III shows, cumulative ovulation rate in women taking metformin was $57.14 \%$ and in CC was $61.11 \%$, the difference was not statistically significant $(P=0.115)$ and cumulative pregnancy rate was also similar in both groups (34.28\% vs $42.85 \%$ in metformin and CC group respectively $(P=0.521)$. 
Table-I

Baseline characteristics of the participants $(N=71)$

\begin{tabular}{lccc}
\hline Characteristics & $\begin{array}{c}\text { Group I (Met) } \\
\mathrm{n}=35\end{array}$ & $\begin{array}{c}\text { Group II (CC) } \\
\mathrm{n}=36\end{array}$ & Significance \\
\hline Age (Yrs)—Mean \pm SD & $27.60 \pm 4.06$ & $26.19 \pm 3.17$ & $0.945^{1}$ \\
BMI -Mean \pm SD & $27.51 \pm 2.99$ & $28.04 \pm 2.81$ & $0.223^{1}$ \\
Obese— $(\%)$ & $10(28.6)$ & $13(36.1)$ & \\
Overweight—n(\%) & $16(45.7)$ & $17(47.2)$ & \\
Normal—n (\%) & $9(25.7)$ & $6(16.7)$ & \\
Waist Hip Ratio—Mean \pm SD & $0.807 \pm 0.083$ & $0.809 \pm 0.082$ & $0.949^{1}$ \\
Type of infertility & & & \\
$\quad$ Primary—n (\%) & $26(74.3)$ & $24(66.7)$ & $0.482^{1}$ \\
$\quad$ Secondary— $(\%)$ & $09(25.7)$ & $12(33.3)$ & \\
Duration of infertility-Months & $34.14 \pm 13.67$ & $31.33 \pm 12.95$ & $0.81^{2}$ \\
\hline
\end{tabular}

1- indicates t-test is performed

2 - indicates chi-square test is performed

Table-II

Baseline hormonal and biochemical parameters among the participants

\begin{tabular}{lccc}
\hline Parameter & $\begin{array}{c}\text { Group- I (Met) } \\
\mathrm{N}=35\end{array}$ & $\begin{array}{c}\text { Group-II (CC) } \\
\text { N=36 } \\
\text { Mean } \pm \text { SD }\end{array}$ & $\begin{array}{c}\text { P-value } \\
\text { (t-test) }\end{array}$ \\
\hline FSH $(\mathrm{mlU} / \mathrm{ml})$ & $7.07 \pm 1.30$ & $6.61 \pm 1.62$ & 0.168 \\
$\mathrm{LH}(\mathrm{mlU} / \mathrm{ml})$ & $10.95 \pm 5.54$ & $11.89 \pm 7.07$ & 0.510 \\
$\mathrm{TSH}(\mu \mathrm{lU} / \mathrm{ml})$ & $2.70 \pm 0.69$ & $2.51 \pm 0.38$ & 0.121 \\
Prolactin $(\mathrm{ng} / \mathrm{ml})$ & $10.39 \pm 9.74$ & $8.53 \pm 1.35$ & 0.236 \\
Blood glucose 2 hrs after $75 \mathrm{gm}$ & $7.40 \pm 0.73$ & $7.50 \pm 0.67$ & 0.513 \\
glucose $(\mathrm{mmol} / \mathrm{L})$ & & & \\
\hline
\end{tabular}

Reference value in the lab of ICMH

$\mathrm{FSH}=(2.8-11.3 \mathrm{mlU} / \mathrm{ml}), \mathrm{LH}=(2.39-6.6 \mathrm{mlU} / \mathrm{ml}), \mathrm{TSH}=(0.4-5 \mu \mathrm{lU} / \mathrm{ml})$,

Prolactin= $(1.92-25.0 \mathrm{ng} / \mathrm{ml})$, Blood sugar 2 hours after $75 \mathrm{gm}$ glucose $(3.6-7.8 \mathrm{mmol} / \mathrm{L})$

Table-III

Ovulation and pregnancy rate in two treatment groups

\begin{tabular}{llccc}
\hline & & Group-I (Metf) \\
& & Group-II (CC) & P-value \\
& & $\mathrm{n}=35$ & 36 & \\
\hline Ovulation $\mathrm{n}(\%)$ & Present & $20(57.14)$ & $22(61.11)$ & 0.115 \\
Pregnancy $\mathrm{n}(\%)$ & Positive & $12(34.28)$ & $15(42.85)$ & 0.521 \\
\hline
\end{tabular}

$\chi^{2}-$ test

Ovulation $=0.733$

Pregnancy+ 0.410

\section{Discussion:}

Present study was undertaken to find out the efficacy of metformin and clomiphene citrate for ovulation and pregnancy achievement in subfertile PCOS women. For this purpose a randomized clinical trial was designed for the period of one year. Seventy one PCOS women diagnosed by Rotterdam criteria, among them in Group-I 35 women received metformin and in Group -II, 36 women received clomiphene citrate.

The cumulative ovulation rate over the six months period was not statistically different between the treatment groups $[57.14 \%$ and $61.11 \%$ in metformin and $\mathrm{CC}$ group respectively, $(\mathrm{P}=0.115)]$. Other 
comparative study between metformin and clomiphene citrate also found similar result ${ }^{19}$. They found that the cumulative ovulation rate per ovulatory cycle was not statistically different $[62.9 \%$ vs. $67.0 \%$ in metformin and $\mathrm{CC}$ group respectively; $\mathrm{P}=0.38$ ]. Another two study done by Velazquez and Fleming have reported an ovulation rate of $86.7 \%$ (13 of 15) and $82 \%$ (37 out of 45) following treatment with metformin in PCOS subfertile women ${ }^{20,21}$. None used hCG for triggering ovulation, which was also similar to the present study.

In contrast to this Legro in his study supports the use of clomiphene citrate alone as first line therapy for subfertile PCOS women ${ }^{3}$. They concluded that clomiphene citrate alone is better than metformin alone or combination of both clomiphene citrate and metformin. Though ovulation, pregnancy and live birth rate were higher in combination of metformin and CC group than metformin and CC alone, it was not significant. Legro, had a large sample size, observed for longer duration (more than two years), and subjects of their study received extended-release metformin which may be less efficacious in women with PCOS than immediate release metformin. They gradually increased the dose of two drugs according to the response. Present study was done in a fixed dose in both groups.

Insulin resistance has a key role in the pathogenesis of PCOS associated infertility ${ }^{22}$. This emphasizes the use of insulin sensitizers as pharmacotherapy for PCOS. Metformin by reducing hyperinsulinemia promotes proper growth of the follicle in contrast to clomiphene citrate, which has no effect on it. Most studies have demonstrated the efficacy of metformin in inducing ovulation ${ }^{20,23,24}$, whereas others disagreed with these findings $s^{25,26,27}$. The advantage of the present study was, all were newly diagnosed cases of PCOS, based on the latest Rotterdam criteria, no one received any fertility treatment earlier. Patients were randomly allocated to the study medications and each patient were followed up for 6 months during the intervention period to observe ovulation and pregnancy. Above mentioned studies mainly looked at the ovulation rate.

In the present study, a significant difference was found in cumulative pregnancy rate between metformin and clomiphene group $60 \%$ versus $33.3 \% ; P=0.02$ which goes in accordance with Palomba ${ }^{19}$. Their study showed that, over six months of treatment a significant difference was observed in the cumulative pregnancy rate $(68.9 \%$ vs $34 \%$ in metformin and CC group respectively; $(P<0.001)$. In contrast Legro, found that pregnancy was approximately twice in clomiphene group compared to metformin group $(29.7 \%$ vs. $12.0 \%)^{3}$. They described multiple follicular recruitment with clomiphene may have an increased opportunity for fertilization and successful implantation. But several studies showed the discrepancy between ovulation and pregnancy rate in PCOS subfertile women treated with clomiphene citrate ${ }^{10,28,29}$. The discrepency is due to its antiestrogenic effect on the cervix and the endometrium, which causes a thickening of the cervical mucus, rendering a hostile environment for sperm transport and thinning of endometrium, which creates an unsuitable site for implantation. An observational comparative study involving 154 women with PCOS noted that metformin was better than CC for ovulation induction and equivalent for pregnancy achievement ${ }^{30}$.

Metformin has been found more effective than clomiphene citrate in treating the anovulatory subfertile PCOS women; with ovulation rate of $80 \%$ and $61.1 \%$ and conception rate of $60 \%$ and $33.3 \%$ respectively.As treatment of infertility is very expensive and cumbersome and many of our patients are from low socio-economic group, we can achieve better result with a less expensive and available drug like metformin, which might be helpful in context of our population.Further multicenter randomized controlled trials with large sample size, good laboratory facilities and provision for longer period of follow up may be conducted to establish the efficacy of metformin for the treatment of subfertile PCOS patients.

\section{References:}

1. Kowalsha I, Kinalsk M, Straczkowski M, Wolczyski S, Kinalska I. Insulin, Leptin, IGF-1 and insulin dependent protein caoncentrations after insulin sensitizing therapy in obese women with PCOS. Eur Journal Endocrinol 2001;144:509-515.

2. Asuncion M, Calvo RM, San Millan JL, Sancho J, Avila S, Escobar and Morreale HF. A prospective study of the prevalence of the polycystic ovary syndrome in unselected Caucasian women from Spain. Journal Clin Endocrinol Metabolism 2000;85:2434-2438. 
3. Legro RS. Clomiphene, metformin or both for infertility in the polycystic ovary syndrome. New Engl Journal Med 2007;356:551-566.

4. Palomba S, Orio Jr F, Falbo A, Russo T, Tolino A, Zullo F. Clomiphene citrate versus metformin as first line approach for the treatment of anovulation in infertile patients with polycystic ovary syndrome. J clin Endocrinol Metab 2007;92:3579-3584.

5. Polson DW Polycystic ovaries - a common finding in normal women. Lancet 1988;1: 870872.

6. Rodin DA, Bano G, Bland JM, Taylor K and Nussey SS. Polycystic ovaries and associated metabolic abnormalities in Indian Subcontinent Asian women. Clin Endocrinol 1998;49(1):91-9.

7. Chowdhury TA, Nargis SF. Polycystic ovary as a cause of sub fertility. Bangla. Journal Obstet Gynaecol 1998;13(2):44-48.

8. Hughes E, Collins J, Vanderkerckhove P. Clomiphene citrate for ovulation induction in women with oligo-amenorrhoea. Cochrane Database Syst. Rev 2000;2: CD000056.

9. Kayshap S, Wells GA, Rosenwaks Z. Insulin sensitizing agents as primary therapy for patients with polycystic ovarian syndrome. Hum Reprod 2004;19:2474-2483.

10. Homburg R. Should patient with PCOS be treated with metformin? A note of cautious optimism. Hum Reprod 2002;17:853-856.

11. Costello MF, Eden JA. A systematic review of the reproductive system effects of metformin in patients with polycystic ovary syndrome. Fertil steril 2003;79:1-13.

12. Sills ES, Perloe M, Palermo GD. Correction of hyperinsulinemia in oligo ovulatory women with clomiphene resistant PCOS; A review of therapeutic rationale and reproductive outcomes. Eur Journal Obstet Gynecol Reprod Biol 2000;91:135-41.

13. Vandermolen DT, Ratt VS, Evans WS, Stoval DW, Kauma SW, Nestler JE. Metformin increases the ovulatory rate and pregnancy rate from clomiphene citrate in patients with PCOS who are resistant to CC alone. Fertil Steril 2001;75:310-5.
14. Kocak M, Caliskan E, Simsir C, Habral A. Metformin therapy improves ovulatory rates, cervical scores and pregnancy rates in CC resistant women with polycystic ovary syndrome. Fertil steril 2002;77:101-6.

15. Glueck CJ, Phillips H, Cameron D, Sieve-Smith L and Wang P. Continuing metformin throughout pregnancy in women with polycystic ovary syndrome appears to safely reduce first-trimester spontaneous abortion: a pilot study. Fertil Steril 2001;175:46-52.

16. Jakubowicz DJ, Iuorno MJ, Jabubowicz $S$, Roberts KA and Nestler JE. Effects of metformin on early pregnancy loss in the PCOS. Journal Clin Endocrinol Metab 2002;87:524-529.

17. Glueck CJ, Wang P, Koyabashi S. Metformin therapy throughout pregnancy reduces development of gestational diabetes in women with polycystic ovary syndrome. Fertil Steril 2002;77:520-525.

18. Glueck CJ, Goldenberg N, Pranikoff J, Loftspring $M$, Sieve $L$ and Wang P. Height, weight and motor - social development during the first 18 months of life in 126 infants born to 109 mothers with polycystic ovary syndrome who conceived on and continued metformin throughout pregnancy- Hum Reprod 2004;19:1323-1330.

19. Palomba S, Orio Jr. Randomized Double - Blind, Controlled Clinical Trial Comparing Clomiphene Citrate and Metformin as the first line treatment for ovulation induction in anovulatory women with PCOS. Journal Clin Endocrinol Metab 2005;90:4068-4074.

20. Velazquez EM, Vandermolen DT, Ratts VS, Evans WS, Stoval DW, Kauma SW, Nestler JE, Acosta A, Mendoza S. Menstrual cyclicity after metformin therapy in polycystic ovary syndrome. Obstet Gynecol 1997;90:392-395.

21. Fleming, Hopkinson ZE, Wallace AM, Greer IA, Sattar N. Ovarian function and metabolic factors in women with oligomenorrhoea treated with metformin in a randomized double blind placebo controlled trial. Journal Clin Endocrinol Metab 2002;87: 569-574.

22. Pesant $\mathrm{MH}$, Baillargeon JP. Ovulation induction in PCOS. Nature Clin PracEndocrinol Metab 2007;3:512-513. 
23. Nestler JE, Jakubowicz DJ, Evans WS, Pasquali R. Effects of metformin on spontaneous and climiphene induced ovulation in the PCOS. $N$ Engl Journal Med 1998;338:1876-1880.

24. Moghetti P, Castello R, Negric C, Tosi F, Perrone $F$, Caputo M. Metformin effects on clinical features, endocrine and metabolic profiles and insulin sensitivity in PCOS. A randomized, double-blind, placebo-controlled 6 month trial, followed by open, long-term clinical evaluation. Journal Clin Endocrinol Metab 2000;85:139-46.

25. Ng EHY, Wal WMS, Ho PC. Effects of metformin on ovulation rate, hormonal and metabolic profiles in women with clomide resistant polycystic ovaries, a randomized, double blinded placebo-controlled trial. Hum Repord 2001;16:1625-31.

26. Ehrmann DA, Cavaghan MK, Imperial J, Sturisj, Rosenfield RL, Polonsky KS. Effects of metformin on insulin secretion, insulin action and ovarian steroidogenesis in women with PCOS. Journal Clin Endocrinol Metab 1997;82:524-30.

27. Yilmaz S, Unal $Y$, Fahrettin K, Ercan A. The effects of metformin on insulin resistance, Clomiphene-induced ovulation and pregnancy rates in women with PCOS. Journal Obstet Gynecol Reprod Biol 2004;113:214-20.

28. Gonen Y, Casper RF. Sonographic determination of a possible adverse effect of clomiphene citrate on endometrial growth. Hum Reprod 1990; 5:670-4.

29. Wramsby $\mathrm{H}$, Fredga $\mathrm{K}$ and Lledholm P. Chromosome analysis of human oocytes recovered from preovulatory follicles in stimulated cycles. New Engl Journal Med 1987;316: 121-124.

30. Neveu N, Granger L, St-Michel P, Lavoie HB. Comparison of clomiphene, metformin or the combination of both for first - line ovulation induction and achievement of pregnancy in 154 women with PCOS. Fertil Steril 2007;87:113-120. 